\title{
Boyuna Uzatılıı̧ Yüzeylerde Dikdörtgensel Oyukların Isı Atımına Etkisi: Bir Hesaplamalı Akışkanlar Dinamiği Analizi
}

\author{
Erdem CÜCE ${ }^{1}$ \\ ${ }^{1}$ Recep Tayyip Erdoğan Üniversitesi, Mühendislik ve Mimarlık Fakültesi, Makine Mühendisliği Bölümü, Rize. \\ e-posta:erdem.cuce@erdogan.edu.tr ORCID ID: http://orcid.org/0000-0003-0150-4705 \\ Geliş Tarihi: 03.04.2020 Kabul Tarihi: 28.10. 2020
}

Öz

\begin{abstract}
Anahtar kelimeler
Isı transferi; Uzatılmış yüzey; Boyuna oyuk; Kanat verimi; Kanat hacmi başına ısı atımı.
\end{abstract}

\footnotetext{
Bu çalışmada, üç farklı zorlanmış taşınım koşulu için ( $h=25,50$ ve $100 \mathrm{~W} / \mathrm{m}^{2} \mathrm{~K}$ ) konvansiyonel ve oyuklu kanatlardan olan ısı transferi ANSYS FLUENT yazılımı ile incelendi ve analizler çeşitli oyuk seviyeleri için tekrarlandı. Analizlerde kanat malzemesi olarak 202.4 W/mK ısıl iletkenliğe sahip alüminyum kullanıldı. Operasyonel durum için fotovoltaik sistemlerin zorlanmış taşınımla soğutulması durumu göz önüne alındı ve bu bağlamda, kanat taban sıcaklığı, standart test koşullarını ( $1000 \mathrm{~W} / \mathrm{m}^{2}$ ışınım akısı, $298.15 \mathrm{~K}$ çevre sıcaklığı) göz önünde bulundurarak $353.15 \mathrm{~K}$ seçildi. Sürekli rejim koşullarında kanat boyunca enerji denklemi $e=10^{-9}$ yakınsama kriteri ile çözüldü. Çalışmada dikkate alınan referans kanat profili $50 \mathrm{~mm}$ boy, $10 \mathrm{~mm}$ yükseklik ve $1 \mathrm{~mm}$ kalınlık ölçülerine sahiptir. Kanat boyunca boylamasına $1 \mathrm{~mm}^{2}{ }^{\prime} l i k$ oyuk çiftleri $(\lambda)$ oluşturuldu ve her bir $\lambda$ değeri için konvansiyonel ve oyuklu kanatlardan olan ısı atımları sayısal olarak belirlendi. Kanat verimi oyuk seviyesinin bir fonksiyonu olarak ayrıca hesaplandı. Sayısal sonuçlar, artan $\lambda$ değeri ile kanattan olan ısı atımının azaldığını, ancak bütün taşınım koşulları için, belirli bir $\lambda$ değerinden sonra birim kanat hacminden olan ısı atımının konvansiyonel kanata kıyasla daha fazla olduğunu gösterdi. Düşük $h$ değerlerinde oyuk etkilerinin daha belirgin olduğu görüldü. $h=25 \mathrm{~W} / \mathrm{m}^{2} \mathrm{~K}$ için konvansiyonel kanattan olan ısı atımı $2.5032 \mathrm{~W}$ iken, $\lambda=24$ için oyuklu kanattan olan ısı atımı 2.6683 W olarak belirlendi. Bu durum ısı atımında yaklaşık \%6.6'lık bir iyileşmeye karşılık gelmektedir.
}

\section{Impacts of Rectangular Perforations in Longitudinal Extended Surfaces on Heat Dissipation: A Computational Fluid Dynamics Analysis}

\begin{abstract}
In this study, for three different forced convection conditions ( $h=25,50$ and $100 \mathrm{~W} / \mathrm{m}^{2} \mathrm{~K}$ ), heat transfer through conventional and perforated fins has been investigated by ANSYS FLUENT software, and the analyses have been repeated for various perforation levels. Aluminium has been utilised as the fin material in the analyses with a thermal conductivity of $202.4 \mathrm{~W} / \mathrm{mK}$. For the operational case, cooling of photovoltaic systems by forced convection has been considered, and in this respect, fin base temperature has been selected to be $353.15 \mathrm{~K}$ by taking standard test conditions $\left(1000 \mathrm{~W} / \mathrm{m}^{2}\right.$ solar intensity, $298.15 \mathrm{~K}$ ambient temperature) into consideration. For steady-state conditions, energy equation has been solved along the fin for the convergence criterion of $e=10^{-9}$. Reference fin profile considered in the research has a $50 \mathrm{~mm}$ length, $10 \mathrm{~mm}$ height and $1 \mathrm{~mm}$ width. Perforation pairs $(\lambda)$ of $1 \mathrm{~mm}^{2}$ have been formed longitudinally along the fin and the heat dissipations from conventional and perforated fins have been numerically determined for each $\lambda$ value. Fin efficiency has also been calculated as a function of perforation level. Numerical results have revealed that heat transfer from the fin decreases with increasing $\lambda$ value, however for each convection condition, heat dissipation per fin volume from the perforated fin is greater in comparison to the conventional fin after a certain $\lambda$ value. Perforation effects have been found more noticeable for the lower $h$ values. For $h=25 \mathrm{~W} / \mathrm{m}^{2} \mathrm{~K}$, heat dissipation from the conventional fin has been determined to be $2.5032 \mathrm{~W}$ whereas the heat transfer through the perforated fin has been found to be $2.6683 \mathrm{~W}$. This case corresponds to an enhancement of about $6.6 \%$ in heat dissipation.
\end{abstract}




\section{Giriş}

Uzatılmış yüzeyler literatürde kanat ya da kanatçık olarak da bilinirler. Esas itibariyle herhangi bir sıcak yüzeyden o yüzeyle temas halindeki ortam havasına olan ISI geçişini maliyet-etkin olarak iyileştirmek maksadıyla kullanılırlar. Bu anlamda özellikle soğutma sistemlerinde yaygın olarak tercih edildikleri söylenebilir. Elektronik devreler, motorlar, türbinler, rejeneratörler, ISI boruları, güneş kollektörleri ve fotovoltaik (PV) sistemler başlıca uygulama alanlarına örnek verilebilir (Cuce et. al. 2019). Uzatılmış yüzeyler yaygın olarak alüminyum ve bakır gibi ısıl iletkenliği yüksek malzemelerden üretilirler. Boyuna ya da radyal olarak tasarlanırlar ve ISI transferi iyileştirme çalışmalarında kullanılan türleri sıklıkla dairesel, üçgensel ve dikdörtgensel kesit alanına sahiptirler (Ali et. al. 2018).

Uzatılmış yüzeylerin soğutma uygulamalarında etkin ve verimli kullanımı, her bir tasarım için geometrik ve operasyonel parametrelerin optimize edilmesini zorunlu kılmaktadır (Guo et. al. 2018). Bu bağlamda bir uzatılmış yüzeyden gerçekleşen ısı transferinde optimizasyon işlemi için iki farklı strateji uygulanmaktadır. Birinci yöntemde, verilen bir kanat hacmi ya da kütlesi için kanattan olan ısı atımı artırılmakta; ikinci yöntemde ise öngörülen bir ISI transfer miktarına yönelik kanat hacmi ya da kütlesi azaltılmaktadır (Yang et. al. 2017). Soğutma sistemlerinde kullanılan uzatılmış yüzeylerden yüksek verim ve düşük maliyet beklentilerine son yıllarda hafiflik ve kompakt sistem detayları eklenmekte, bu anlamda birim kanat hacmi ya da kütlesinden olan ısı atımının boyut optimizasyonu ile iyileştirilmesi uluslararası literatürde yoğun olarak çalışıımaktadır. Örneğin bir çalışmada, kanat kesitindeki parabolik adım değişikliklerinin ISI atımına etkisi teorik olarak analiz edilmekte ve farklı taşınım koşulları için aynı ısı atım performansını veren fakat \%3 ile \%14 arasında daha az kanat malzemesi kullanan geometrik çözümler sunulmaktadır (Kobus and Cavanaugh 2006). Başka bir çalışmada, boyuna uzatılmış yüzeylerde kanat içerisinde hacimsel ISI üretiminin kanattan olan ISI atımına ve kanat verimine etkisi çalışımaktadır
(Azarkish et. al. 2010). Farklı taşınım ve ışınım koşulları altında, optimum kanat geometrileri ve bu kanat geometrilerine karşılık gelen ISı transfer miktarları analiz edilmektedir. Elde edilen sonuçlar, kanat içerisinde artan hacimsel Isı üretimi ile kanat veriminin düştüğünü göstermektedir. Diğer bir çalışmada, dikdörtgensel kesitli kanatlarda aynı kanat kütlesini referans alarak kanat kesitindeki basamak değişiminin kanattan olan ISı atımına ve kanat verimine etkisi incelenmektedir (Cuce and Cuce 2014). Elde edilen sonuçlara göre, tek basamak değişikliği ile kanat verimi \%2, kanattan olan ısı atımı ise \%3.4 oranında iyileşmektedir.

Son yıllarda boyuna kanatlarda oyuk ile birim kanat hacmi ya da kütlesinden olan Isı transferini, kanat verimini ve kanat etkinliğini iyileştirmeye yönelik çalışmalar dikkat çekmektedir. Ancak söz konusu çalışmalarda oyukların sıklıkla kanat boyuna dik ve kanat et kalınlığı boyunca dikkate alındığı anlaşılmaktadır (Maji et. al. 2019). Örneğin bir çalışmada dairesel, üçgensel ve dikdörtgensel oyukların farklı taşınım koşulları altında ISI transferine olan etkileri sayısal ve deneysel olarak incelenmektedir (Ibrahim et. al. 2018). Sonuçlar konvansiyonel kanatla karşılaştırımaktadır. Elde edilen sonuçlara göre boyuna oyukların ISI kuyularında ısı transfer katsayılarını yaklaşık \%35 ile \%51 arasında iyileştirildiği vurgulanmaktadır. Çalışılan oyuk tipleri arasında en iyi sonucu dairesel tip verirken, en kötü sonuç üçgensel formdan elde edilmektedir. Dairesel tip oyuk özellikle iğne uçlu kanatlarda ISı kuyularının ISı atım performanslarını iyileştirmek için kullanılmaktadır (Bakhti and SiAmeur 2019). Dairesel kanatlarda oyukların ISI transfer miktarına etkisi sıklıkla çalışılmakta ve elde edilen bulgular diğer kanatlarla karşılaştırılmaktadır. Rüzgâr tünelinde yürütülen deneysel çalışmada oyuklu kanatların, sistem için ağırlık düşüşü sağlamasının yanında ıSı atımına pozitif etki ettiği tespit edilmektedir (Nadooshan et. al. 2018). 0.05 ve $0.1 \mathrm{~kg} / \mathrm{s}$ kütlesel debi değerleri için, Isı transfer miktarındaki iyileşmeler $\% 8.78$ ve $\% 9.23$ olarak belirlenmektedir. Başka bir çalışmada boyuna uzatılmış yüzeylerde parabolik oyukların birim kanat malzemesinden olan Isı atımına etkisi sayısal olarak incelenmektedir (Cuce and Cuce 2013a). Elde edilen 
sonuçlar, artan oyuk seviyesi ile birim kanattan olan ISI transferinin önemli ölçüde iyileştiğini göstermektedir. Benzer şekilde, kanat veriminin parabolik oyuk düzeyi ile doğrusal olarak arttığı görülmektedir.

Uzatılmış yüzeylerden ısı transferinde oyuk etkileri alanındaki literatür detaylıca incelendiğinde, farklı geometri ve sayılarda kanat boyunca Isı geçişine dik yönde oluşturulan tasarımlarla çeşitli analizlerin yürütüldüğü görülmektedir. Kanat içerisinde söz konusu oyuk yapılarının birim kanat kütlesinden olan ISı atımına klasik kanada kıyasla hatırı sayılır ölçüde olumlu etki yaptığı bilinmektedir. Ancak bu tür oyuk tasarımları seri üretime uygun olmayıp, klasik kanat üretimine nazaran ekonomikliği olumsuz etkilemektedir. Bu çalışma kapsamında, piyasada en yaygın kullanım alanına sahip dikdörtgen kesitli kanatlarda boyuna ancak kanat dış cidarlarında oluşturulacak oyukların ISı atımına, kanat verimine ve kanat etkinliğine olan muhtemel etkileri sayısal olarak analiz edilmiştir. Bu tarz bir oyuk oluşumu, seri üretime uygun olup, Isı transferi ve hafiflik açısından makul bir tasarımdır ve literatürde ilk kez bu çalışma kapsamında ele alınmıştır.

Bu çalışmanın ana amacı, daha önceki literatürde kanat içerisinde ISı iletimine dik yönde ve kanat et kalınlığı boyunca düşünülen oyukların aksine, kanat boyunca ancak kanat dış kenarlarında ele alınacak dikdörtgensel oyukların, birim kanat hacminden olan ISı atımına, kanat verimine ve kanat etkinliğine olan muhtemel etkilerini, bir hesaplamalı akışkanlar dinamiği analiz programı olan ANSYS FLUENT ile araştırmak ve sonuçları referans durumu teşkil eden oyuksuz konvansiyonel kanat ile farklı senaryolar üzerinden karşılaştırmaktadır. Önceki çalışmaların aksine kanat dış kenarlarında oyuk oluşturma seri üretime daha uygun ve daha ekonomik bir yaklaşımdır. Oyuklu kanatlar önemli ölçüde kütleden kazanç temin ettiği için ısıl sistemlere ekstra yük getirmeden arzu edilen ısıl regülasyonu sağlama hususunda önemli bir potansiyele sahiptir. Mevcut çalışma bu potansiyeli sayısal olarak analiz etmeyi amaçlamaktadır.

\section{Materyal ve Metot}

\subsection{Teorik Analiz}

Uzatılmış yüzeyler, çevrelerine göre daha yüksek sıcaklıkta bulunan ve etkin soğutulması gereken yüzeylerde, ısı transfer yüzey alanının artırılması ile çevre havasına birim zamanda transfer edilen ISI miktarının iyileşmesine katkı yapan ısı kuyularıdır. Şekil 1'de gösterilen dikdörtgen kesitli kanatta, taşınım ve ışınım koşulları altında en genel halde bir boyutta enerji dengesi şu şekilde yazılabilir (Incropera and DeWitt, 2010):

$\frac{d^{2} T}{d x^{2}}-\left(\frac{1}{A_{c}} \frac{h}{k} \frac{d A_{s}}{d x}\right)\left(T-T_{\infty}\right)-\left(\frac{1}{A_{c}} \frac{\varepsilon \sigma}{k} \frac{d A_{s}}{d x}\right)\left(T^{4}-T_{\infty}{ }^{4}\right)=0$

Eşitlik (1)'de $T(x)$, kanat boyunca herhangi bir $x$ değerine karşılık gelen sıcaklığı ifade etmektedir. Öte yandan $h, k, \varepsilon$ ve $\sigma$ sırasıyla ortamın ısı taşınım katsayısını, kanat malzemesinin ısı iletim katsayısını, kanatın ışınım yayma oranını ve Stefan-Boltzmann sabitini ifade etmektedir. $T_{\infty}$ çevre havası sıcaklığıdır.

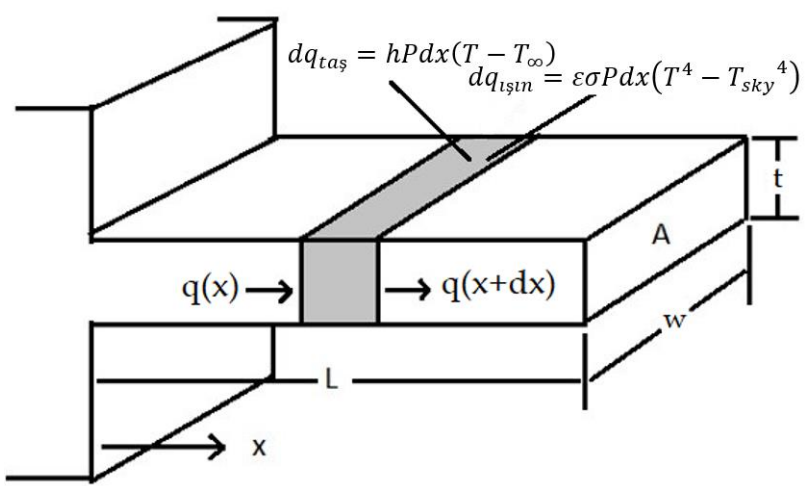

Şekil 1. Uzatılmış yüzeylerden ısı transferinde enerji dengesi (Incropera and DeWitt 2010).

Eşitlik (1)'de boyuna dikdörtgensel kanat profili için $d A_{s} / d_{x}$ teriminin kanat çevresine $(P)$ eşit olduğundan hareketle, Işınımla Isı geçişi inmal edildiğinde ve kanat malzemesinin Isı iletim katsayısının sabit olduğu düşünüldüğünde, kanat için bir boyutlu enerji dengesi eşitliği Eşitlik (2)'deki gibi basitleştirilebilir:

$\frac{d^{2} T}{d x^{2}}-\frac{h P}{k A_{c}}\left(T-T_{\infty}\right)=0$

Eşitlik (2)'de $T$ - $T_{\infty}$ ifadesi $\theta$ ile yer değiştirilirse Eşitlik (3)'teki ifade elde edilir. 
$\frac{d T}{d x}=\frac{d \theta}{d x}, \frac{d^{2} T}{d x^{2}}=\frac{d^{2} \theta}{d x^{2}}$

Buradan hareketle ilgili sadeleştirmelerde Eşitlik (4)'teki ifade elde edilir.

$\frac{d^{2} \theta}{d x^{2}}-\frac{h P}{k A_{c}} \theta=0$

Eğer $h P / k A_{c}$ terimi $m^{2}$ ile yer değiştirilirse

$\frac{d^{2} \theta}{d x^{2}}-m^{2} \theta=0$

sadeleşmiş ifadesi elde edilir. Eşitlik (5)'teki 2. mertebeden diferansiyel denklemin çözümü

$\theta=C_{1} e^{-m x}+C_{2} e^{m x}$

olarak elde edilir. Eşitlik (6)'daki $C_{1}$ ve $C_{2}$ integrasyon sabitleri olup, değerleri ilgili sınır koşullarından hesaplanmaktadır. Uzatılmış yüzeyler sıklıkla belirli bir başlangıç sıcaklığına sahip sıcak yüzeyin doğal ya da zorlanmış taşınımla soğutuıması uygulamalarında karşımıza çıktığı için, $C_{1}$ ve $C_{2}$ integrasyon sabitlerinin hesaplanmasında, kanat dibinde sabit yüzey sıcaklığı sınır koşulu, kanat ucunda ise taşınımla ısı geçişi sınır koşulu Eşitlik (7, 8 ve 9)'daki gibi yazılır.

$\theta=T_{b}-T_{\infty}=\theta_{b}$

$-\left.k A_{c} \frac{d T}{d x}\right|_{x=L}=h A_{c}\left(T(L)-T_{\infty}\right)$

$-\left.k \frac{d \theta}{d x}\right|_{x=L}=h \theta(L)$

Verilen sınır koşulları altında diferansiyel denklem çözüldüğünde kanat boyunca sıcaklık dağılımı ve kanattan olan ISı geçişi Eşitlik (10 ve 11)'deki gibi elde edilir: $\frac{\theta}{\theta_{b}}=\frac{\cosh m(L-x)+\frac{h}{m k} \sinh m(L-x)}{\cosh m L+\frac{h}{m k} \sinh m L}$

$$
Q=\sqrt{h P k A_{c}} \theta_{b} \frac{\sinh m L+\frac{h}{m k} \cosh m L}{\cosh m L+\frac{h}{m k} \sinh m L}
$$

Uzatılmış yüzeylerde kanat verimi, kanattan atılan ısının, o koşullarda kanattan atılabilecek maksimum ısıya oranı olarak tanımlanmaktadır.

$\eta=\frac{Q}{Q_{m}}$

Eşitlik (12)'de $Q_{m}$, kanat boyunca sıcaklık, kanat taban sıcaklığına eşit olduğu durumda kanattan atılan ısıyı ifade etmektedir. Kanat etkinliği ise, kanattan atılan ısının, kanat olmaması durumunda taşınımla kanat tabanından atılan ısıya oranı olarak tanımlanmaktadır. Eşitlik (13)'te $Q_{t}$, kanatsız durumda kanat dibinden olan ISI atımını vermektedir.

$\varepsilon=\frac{Q}{Q_{t}}$

\subsection{Oyuklu Dikdörtgensel Kanat Geometrisi}

$\mathrm{Bu}$ çalışma kapsamında kanat boyunca kanat dibinden itibaren göz önünde bulundurulan dikdörtgensel oyuk çiftlerinin birim kanat hacminden olan Isı atımına, kanat verimine ve kanat etkinliğine olan etkileri sayısal olarak çalışılmaktadır. Her bir oyuk çifti $(\lambda)$ sayısı için elde edilen bulgular Şekil 2'de gösterildiği gibi konvansiyonel durumu temsil eden oyuksuz kanat ile karşılaştırılmaktadır. 


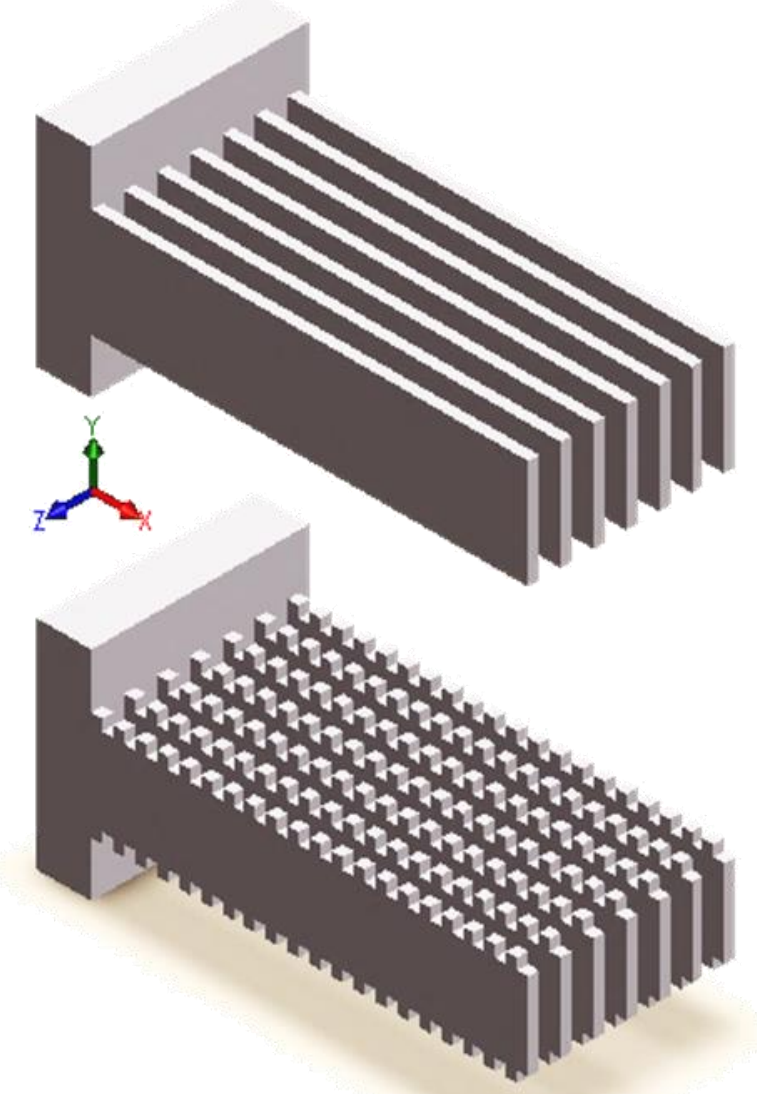

Şekil 2. Konvansiyonel ve oyuklu uzatılmış yüzeylerin oluşturduğu temsili ısı kuyuları.

Çalışmada ele alınan problem PV modüllerin aktif soğutulması ve bu bağlamda ısı kuyularındaki oyuk etkileri olduğundan, referans kanat geometrisi için PV sistemlerde kullanılan kanat profillerine benzer bir yaklaşım tercih edilmiştir.

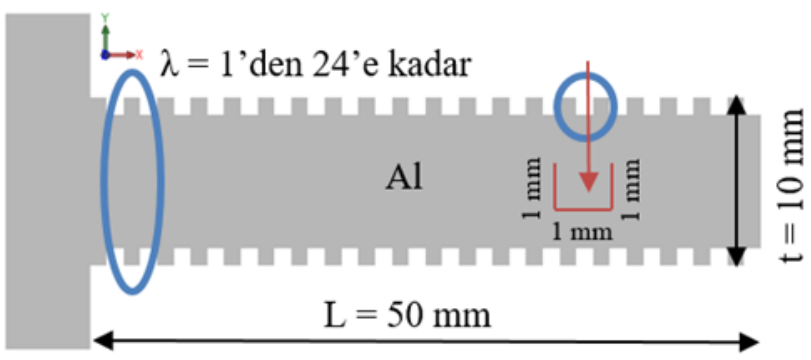

Şekil 3. Çalışmada kullanılan kanat geometrisi.

$\mathrm{Bu}$ bağlamda, kanat boyu (L) $50 \mathrm{~mm}$, kanat yüksekliği (t) $10 \mathrm{~mm}$ ve kanat genişliği (w) $1 \mathrm{~mm}$ seçilmektedir. Şekil 3'te verilen oyuklu kanat için oyuk çifti sayısı $(\lambda)$ kanat dibinden itibaren 1 'den 24'e kadar değiştirilmekte ve analizler her bir durum için tekrarlanmaktadır. Çalışma kapsamında kanat boyunca kanat kenarı üzerinde $1 \mathrm{~mm}^{2}$ yüzey alanına sahip dikdörtgensel oyuk çiftleri ön görülmektedir. Kanat malzemesi olarak $202.4 \mathrm{~W} / \mathrm{mK}$ Isıl iletkenliğe sahip alüminyum tercih edilmektedir. Bunun sebebi kanatçık üretiminde en yaygın kullanılan malzemenin saf alüminyum ve alüminyum alaşımları olmasıdır. Alüminyum bakıra göre çok daha hafif, ucuz ve kolay işlenebilen bir malzemedir. Bu nedenle bu tarz uygulamalarda sıklıkla tercih edilmektedir. Problemde sınır koşulları olarak kanat tabanında sabit yüzey sıcaklığı ve kanat ucunda taşınım sınır koşulu kabulü yapılmıştır. PV modüllerin standart test koşullarında hücre sıcaklığı 70-90 ${ }^{\circ} \mathrm{C}$ arasında değişmektedir. Bu sebeple kanat taban sıcaklığı ortalama bir değer olarak $353.15 \mathrm{~K}$ alınmaktadır. Kanattan ortama ISı atımında ise üç farklı zorlanmış taşınım koşulu için ( $h=25,50$ ve 100 $\mathrm{W} / \mathrm{m}^{2} \mathrm{~K}$ ) analizler tekrarlanmaktadır.

\subsection{Hesaplamalı akışkanlar dinamiği analizi}

Çalışmada konvansiyonel ve oyuklu kanatlardan olan ISı transferi analizlerinde güvenilir ve gerçekçi bir hesaplamalı akışkanlar dinamiği analiz programı olan ANSYS FLUENT 17.1 kullanılmaktadır. Sürekli rejim koşullarında kanat boyunca enerji denklemi $e=10^{-9}$ yakınsama kriteri ile çözülmektedir. Ağlamada dikdörtgensel ağlar tercih edilmekte ve üç farklı hücre sayısında yürütülen analizlerle ağ bağımsız çözüm elde edilmektedir. İlgili analizlerde hücre sayıları $2,000,000,3,000,000$ ve 3,750,000 olarak belirlenmiştir. Her bir oyuk ayrıtı $1 \mathrm{~mm}$ olduğu için $100 \mu \mathrm{m}$ ayrıta sahip hücre elemanlarıyla sayısal hesaplamalar yürütülmüştür. Optimum ağda (her mm için 10 ağ noktası) oyuksuz kanattan olan teorik ISı transfer miktarı $\mathrm{h}=25 \mathrm{~W} / \mathrm{m}^{2} \mathrm{~K}$ için 1.2501 W olarak hesaplanırken, sayısal yolla elde edilen Isı atımı 1.2516 W olarak belirlenmektedir. Bu da teorik ve sayısal sonuçlar arasında konvansiyonel durum için \%0.12 mertebesinde bir hataya karşlık gelmektedir. Teorik hesaplamalarda Maple yazılımı kullanılmıştır.

\section{Bulgular ve Tartışma}

Sonuçların ilk bölümünde sürekli rejimde oyuklu ve klasik kanat içerisinde statik sıcaklık kontörleri Şekil 4'teki gibi sunulmaktadır. Ele alınan kanat profiline ait boyutsal parametreler ve işletme koşullarına ait karakteristikler şu şekildedir: Kanat boyu L=50 mm, 
kanat yüksekliği t=10 mm, kanat genişliği $\mathrm{w}=1 \mathrm{~mm}$, oyuk çifti sayısı $\lambda=24$, kanat taban sıcaklığı $\mathrm{T}_{\mathrm{b}}=$ $353.15 \mathrm{~K}$, serbest akış ortam sıcaklı̆̆ı $T_{\infty}=298.15 \mathrm{~K}$, ısı taşınım katsayısı $\mathrm{h}=25 \mathrm{~W} / \mathrm{m}^{2} \mathrm{~K}$, kanat malzemesi alüminyum ve ISı iletim katsayısı $k=202.4 \mathrm{~W} / \mathrm{mK}$. Oyuk etkisi ile kanat boyunca sıcaklık dağılımının önemli ölçüde etkilendiği anlaşılmaktadır. İlgili sonuçlar $h=25 \mathrm{~W} / \mathrm{m}^{2} \mathrm{~K}$ zorlanmış taşınım koşulu için elde edilmiş olup, $\lambda=24$ için kanat kütlesindeki belirgin düşüşe dikkat çekilmektedir. Oyuk kesiti incelenirse, uzatılmış yüzey boyunca göz önünde bulundurulan oluklama işleminin taşınımla ISI geçişinde toplam ISI transfer yüzey alanını değiştirmediği anlaşılacaktır. Ancak malzemedeki boyuna kütle düşüşünün ISı atımını bir miktar kötüleştireceği, bununla birlikte birim hacim ya da kütle başına ISı transferinin artacağı tahmin edilmektedir ki bu problem mevcut araştırmanın yenilikçi yönünü ortaya koymaktadır.
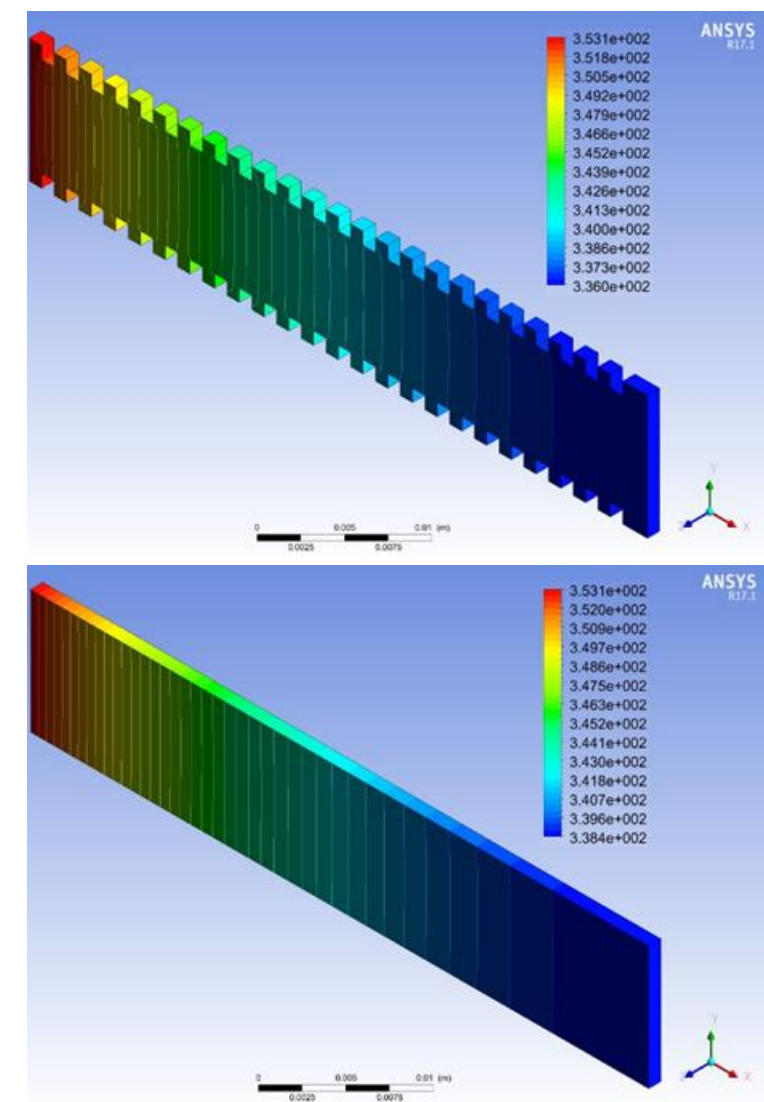

Şekil 4. Konvansiyonel ve oyuklu uzatılmış yüzeyler için kanat boyunca sıcaklık dağılımı.

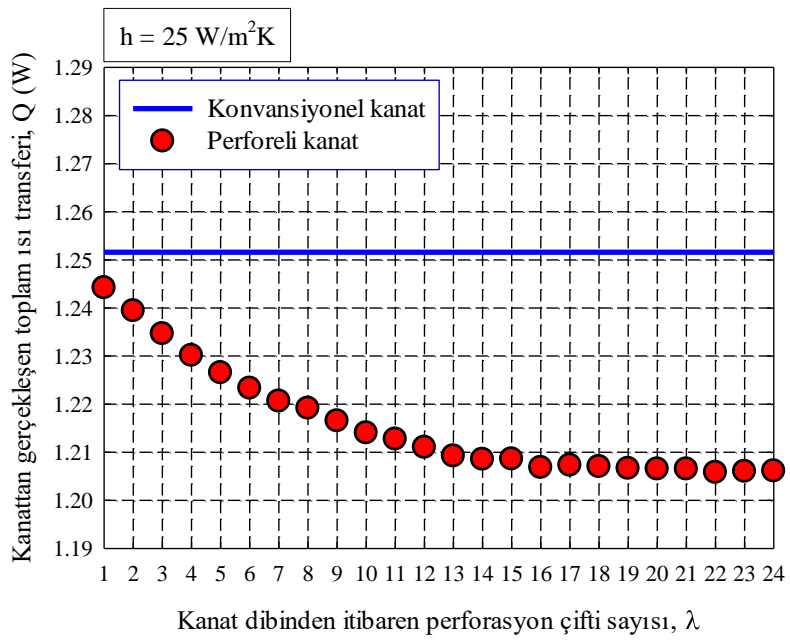

Şekil 5. $h=25 \mathrm{~W} / \mathrm{m}^{2} \mathrm{~K}$ için konvansiyonel ve farklı $\lambda$ değerlerine sahip oyuklu kanattan atılan toplam ısı miktarı.

Üç farklı zorlanmış taşınım koşulu için ( $h=25,50$ ve $100 \mathrm{~W} / \mathrm{m}^{2} \mathrm{~K}$ ) klasik ve oyuklu kanattan olan toplam ISI geçişi ve birim kanat hacmi başına ISI geçiş miktarları sayısal olarak elde edilmiştir. Şekil 5'te $\mathrm{h}=25 \mathrm{~W} / \mathrm{m}^{2} \mathrm{~K}$ için ilgili karşılaştırmalar sunulmuştur. Oyuksuz kanattan atılan ısı miktarı $1.2516 \mathrm{~W}$ olarak belirlenmiştir. Öte yandan, artan $\lambda$ değeri ile oyuklu kanattan olan ISı geçişi 1.2442 W'tan 1.2061 W'a üstel olarak azalma göstermekte ve bu değere yakınsamaktadır. illk bakışta oyuklu kanadın daha düşük performans gösterdiği düşünülebilir. Ancak, Şekil 6'da sunulan birim hacim başına ısı transfer miktarları dikkate alındığında, $\mathrm{h}=25 \mathrm{~W} / \mathrm{m}^{2} \mathrm{~K}$ için $\lambda=$ 6 'dan itibaren oyuklu kanadın kayda değer şekilde daha üstün performans gösterdiği anlaşılmaktadır. Birim kanat hacmi başına ISI transferi (Ф) klasik kanat için $2.5032 \mathrm{~W} / \mathrm{cm}^{3}$ iken, $\lambda=24$ için bu değer $2.6683 \mathrm{~W} / \mathrm{cm}^{3}$ olarak tespit edilmiştir. 


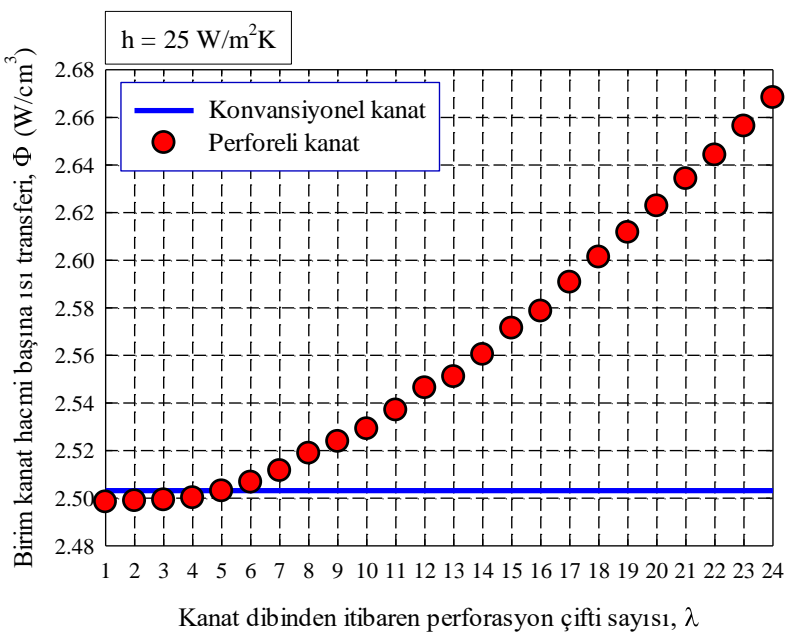

Şekil 6. $h=25 \mathrm{~W} / \mathrm{m}^{2} \mathrm{~K}$ için konvansiyonel ve farklı $\lambda$ değerlerine sahip oyuklu kanattan birim kanat hacmi başına atılan toplam ısı miktarı.

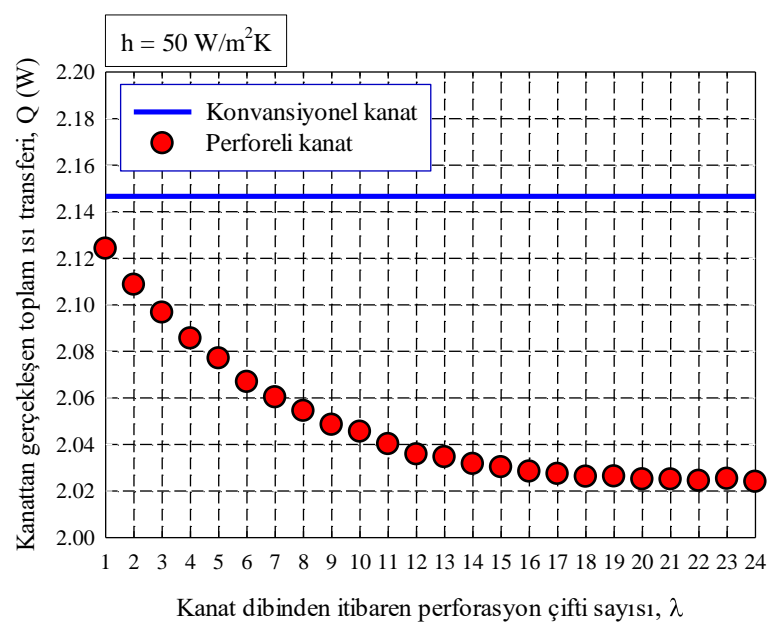

Şekil 7. $h=50 \mathrm{~W} / \mathrm{m}^{2} \mathrm{~K}$ için konvansiyonel ve farklı $\lambda$ değerlerine sahip oyuklu kanattan atılan toplam Isı miktarı.

Şekil 7'de $\mathrm{h}=50 \mathrm{~W} / \mathrm{m}^{2} \mathrm{~K}$ için kanatlardan olan toplam ISI transferi birbiriyle kıyaslamalı olarak verilmektedir. Oyuksuz kanattan atılan Isı miktarı 2.1456 W olarak hesaplanmıştır. Öte yandan, artan $\lambda$ değeri ile oyuklu kanattan olan Isı geçişi 2.1241 W'tan 2.0239 W'a üstel olarak azalma göstermekte ve $\lambda=20^{\prime}$ den sonra bir değişiklik yaşanmamaktadır. Benzer şekilde ilgili verilerden hareketle oyuklu kanadın daha düşük performans gösterdiği zannedilebilir. Ancak, Şekil 8'de sunulan birim hacim başına ısı transfer miktarları dikkate alındığında, $\mathrm{h}=50 \mathrm{~W} / \mathrm{m}^{2} \mathrm{~K}$ için $\lambda=14^{\prime}$ ten itibaren oyuklu kanadın kayda değer şekilde daha üstün performans gösterdiği anlaşılmaktadır. Birim kanat hacmi başına ISI transferi (Ф) klasik kanat için $4.2932 \mathrm{~W} / \mathrm{cm}^{3}$ iken, $\lambda=24$ için bu değer $4.4758 \mathrm{~W} / \mathrm{cm}^{3}$ olarak elde edilmiştir. $h=25 \mathrm{~W} / \mathrm{m}^{2} \mathrm{~K}$ koşuluna kıyasla, $\mathrm{h}=50$ $\mathrm{W} / \mathrm{m}^{2} \mathrm{~K}^{\prime}$ de kanat hacmi başına ısı atımının oyuklu kanatlarda klasik kanat durumuna göre daha büyük $\lambda$ değerlerinde ( $6^{\prime}$ dan $14^{\prime}$ e) iyileştiği görülmüştür. Elbette ki bu durum taşınım koşullarındaki iyileşmenin bir sonucudur. Artan $\mathrm{h}$ değerleriyle kanat boyunca düşünülen oyukların klasik kanada kıyasla ISı atımındaki etkinliği azalmaktadır. Bu sebeple oyuklu kanatların, aktif yöntemlerin aksine, pasif soğutma uygulamalarında daha etkin çalışacağı rahatlıkla söylenebilir (Grubisic-Cabo et. al. 2018).

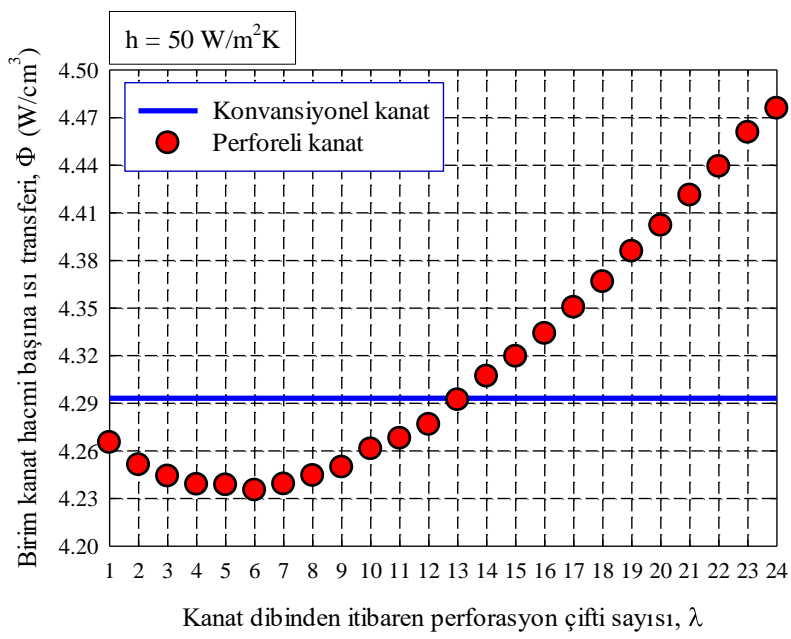

Şekil 8. $h=50 \mathrm{~W} / \mathrm{m}^{2} \mathrm{~K}$ için konvansiyonel ve farklı $\lambda$ değerlerine sahip oyuklu kanattan birim kanat hacmi başına atılan toplam ısı miktarı.

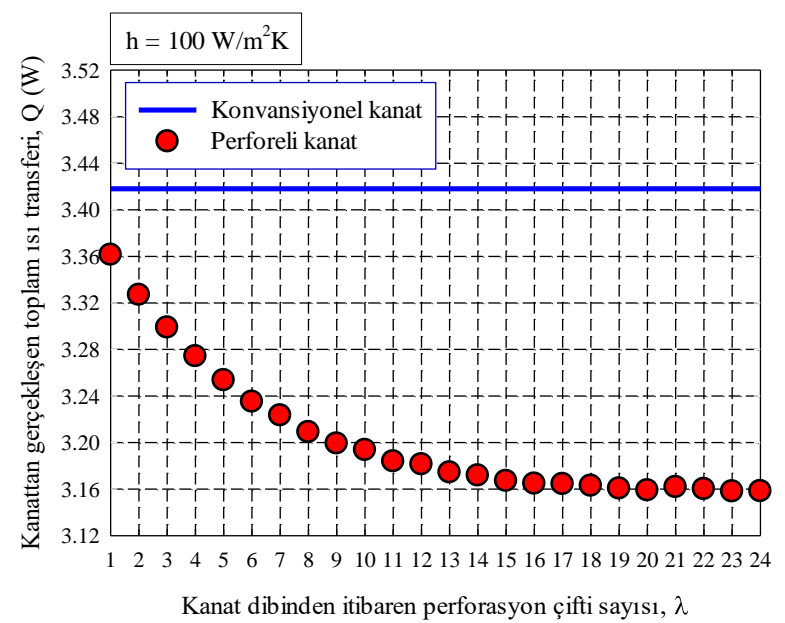

Şekil 9. $h=100 \mathrm{~W} / \mathrm{m}^{2} \mathrm{~K}$ için konvansiyonel ve farklı $\lambda$ değerlerine sahip oyuklu kanattan atılan toplam ısı miktarı.

Şekil 9' da $h=100 \mathrm{~W} / \mathrm{m}^{2} \mathrm{~K}$ için kanat profillerinden olan toplam ISı transferi birbiriyle karşılaştırmalı olarak sunulmaktadır. Klasik kanattan atılan ISI miktarı 3.4181 W olarak belirlenmektedir. Öte yandan, $\operatorname{artan} \lambda$ değeri ile oyuklu kanattan olan ISI 
geçişi 3.3613 W'tan 3.1582 W'a üstel olarak azalmaktadır. Şekil 10'da birim hacim başına ISI transfer miktarları dikkate alındığında, $\mathrm{h}=100$ $\mathrm{W} / \mathrm{m}^{2} \mathrm{~K}$ için $\lambda=19^{\prime}$ dan itibaren oyuklu kanadın kayda değer şekilde daha üstün performans gösterdiği anlaşılmaktadır. Birim kanat hacmi başına ISI transferi (Ф) klasik kanat için $6.8362 \mathrm{~W} / \mathrm{cm}^{3}$ iken, $\lambda=24$ için bu değer $6.9871 \mathrm{~W} / \mathrm{cm}^{3}$ olarak elde edilmiştir. Ancak dikkat edilecek olursa, zorlanmış taşınım koşulları belirginleştikçe, oyuklu kanatların klasik kanat durumuna göre birim hacim başına ISI atımındaki üstünlüğü azalmaktadır.

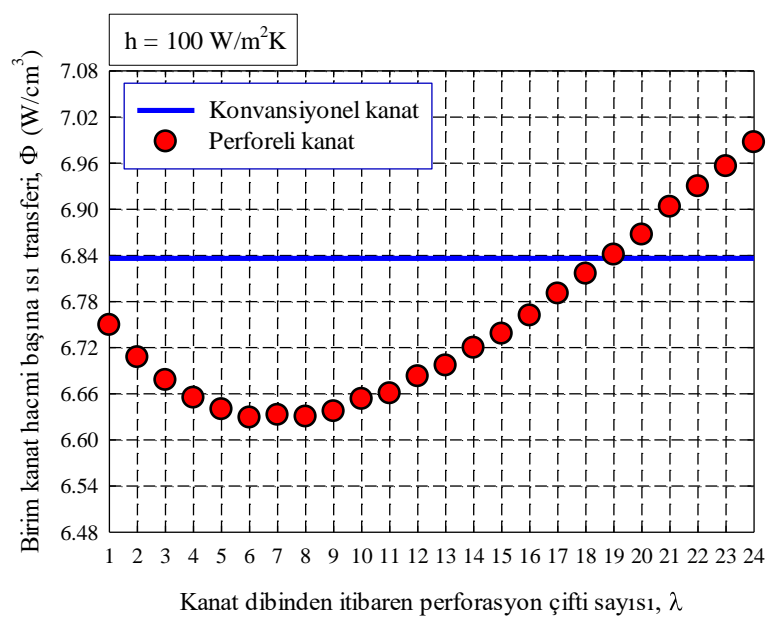

Şekil 10. $h=100 \mathrm{~W} / \mathrm{m}^{2} \mathrm{~K}$ için konvansiyonel ve farklı $\lambda$ değerlerine sahip oyuklu kanattan birim kanat hacmi başına atılan toplam ısı miktarı.

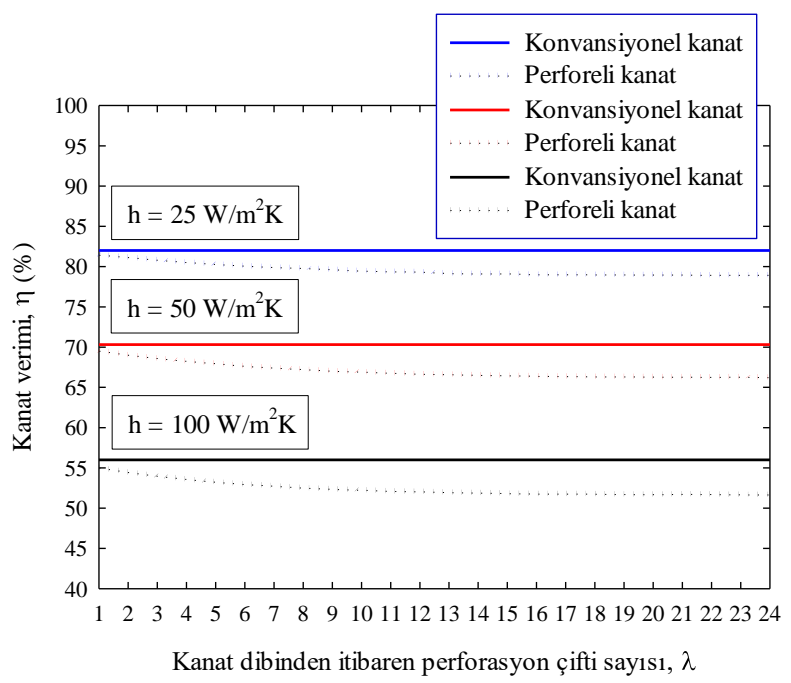

Şekil 11. Üç farklı zorlanmış taşınım koşulu için konvansiyonel ve farklı $\lambda$ değerlerine sahip oyuklu kanat verimlerinin kıyaslanması.

Şekil 11'de sunulan verim değerlerinden anlaşılacağı üzere gerek klasik gerekse oyuklu kanat için artan ISI taşınım katsayısı ile kanat verimi azalmaktadır. h-25, 50 ve $100 \mathrm{~W} / \mathrm{m}^{2} \mathrm{~K}$ için konvansiyonel kanat verimi sırasıyla \%82.0, \%70.3 ve \%55.9 olarak hesaplanmıştır. Öte yandan, oyuklu kanatta $\operatorname{artan} \lambda$ değeri ile kanat veriminin üstel olarak azaldığı görülmüştür. Nihayetinde her üç durumda da kanat verimi belirli bir değere yakınsamaktadır. Bu değerler $h=25,50$ ve $100 \mathrm{~W} / \mathrm{m}^{2} \mathrm{~K}$ için sırasıyla $\% 79.0, \% 66.3$ ve $\% 51.7$ olarak hesaplanmıştır.

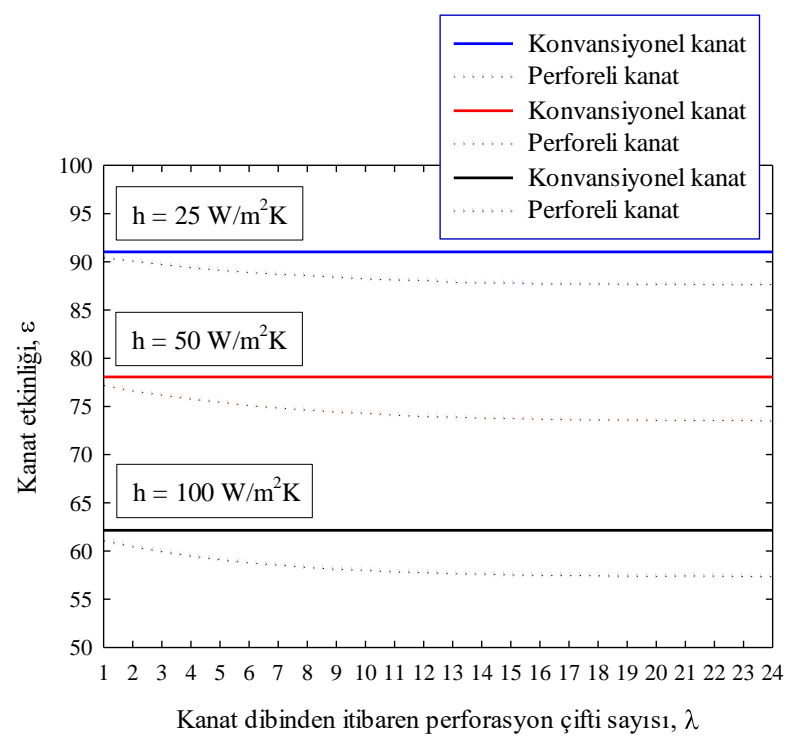

Şekil 11. Üç farklı zorlanmış taşınım koşulu için konvansiyonel ve farklı $\lambda$ değerlerine sahip oyuklu kanat etkinliklerinin kıyaslanması.

Kanat verimine benzer bir eğilim kanat etkinliği $(\varepsilon)$ için de elde edilmiştir. Şekil 12 'de gösterildiği gibi artan ısı taşınım katsayısı ile $\varepsilon$ azalmaktadır. Artan oyuk seviyesi ile kanat etkinliği üstel olarak azalmaktadır. $h=25,50$ ve $100 \mathrm{~W} / \mathrm{m}^{2} \mathrm{~K}$ için konvansiyonel kanat etkinliği sırasıyla 91.0, 78.1 ve 62.1 olarak elde edilmiştir. Öte yandan, $\lambda=24$ için aynı taşınım koşullarında $\varepsilon$ değeri $87.7,73.6$ ve 57.4 olarak hesaplanmıştır. Elde edilen sonuçlar göstermektedir ki oyuklu kanatlar birim hacim başına kanattan atılan ısı miktarına kayda değer ölçüde olumlu etki etmektedir. Bu anlamda hafiflik gerektiren aktif ya da pasif soğutma uygulamaları için anahtar bir çözüm olarak düşünülebilirler. Bunun yanında konvansiyonel kanata kıyasla verim ve etkinlik değerleri rekabetçi bir eğilim sergilemektedir. Özetle başta PV sistemlerin maliyet-etkin soğutulması olmak üzere (Cuce and Cuce 2013b, Cuce and Cuce 2013c) farklı 
uygulamalarda temel performans parametrelerinin iyileştirilmesinde tercih edilebilirler. Klasik dikdörtgensel kanatçıkların, bina entegreli PV sistemlerde hücre tipine bağlı olarak pasif soğutma ile çıkış gücünde \% 5'e varan iyileşme sağladığı önceki sayısal çalışmalardan anlaşıımaktadır. Oyuklu kanat tasarımı ile arzu edilen elektriksel iyileşmenin daha hafif sistem konfigürasyonları ile yapılabileceği bu çalışmadan çıkarılabilecek önemli bir sonuçtur.

Artan ISı taşınım katsayısı değerlerinde, oyuk etkilerinin yüksek $\lambda$ değerlerinde belirgin olduğu görülmektedir. Bunun sebebi, doğal taşınımdan zorlanmış taşınıma geçildikçe Nusselt sayılarında artış meydana gelmesi, bir diğer ifadeyle ISI geçişinde taşınım etkilerinin iletim etkilerine baskınlığının artmasıdır. Yüksek taşınım koşulları altında, uzatılmış yüzeylerin ısı atımındaki rolünün azalması beklenen bir durumdur.

\section{Sonuç ve Öneriler}

Bu çalışmada kanatlarda boyuna oyukların kanattan olan toplam ISı geçişine ve birim kanat hacminden olan ISI atımına etkileri sayısal olarak incelenmektedir. Çalışmadan elde edilen bulgular ve tavsiyeler şu şekilde sıralanabilir:

- Uzatılmış yüzeylerde kanat kenarı boyunca ele alınan dikdörtgensel oyuklar kanat yapısında ciddi ağırık düşüşü sağlamaktadır.

- Oyuklu kanatlarda konvansiyonel kanata kıyasla kanattan olan toplam ısı atımı azalmaktadır. Ancak, birim kanat hacmi başına ISı atımı referans alınırsa, oyuklu kanatlar oldukça etkin konfigürasyonlar olarak kendini göstermektedir.

- $\quad h=25 \mathrm{~W} / \mathrm{m}^{2} \mathrm{~K}$ için, oyuksuz kanattan atılan ISI miktarı $1.2516 \mathrm{~W}$ olarak hesaplanmaktadır. Artan $\lambda$ değeri ile oyuklu kanattan olan ISI geçişi 1.2442 W'tan 1.2061 W'a üstel olarak azalma göstermektedir.

- $\quad$ Ancak, birim kanat hacmi başına ısı transferi (Ф) klasik kanat için $2.5032 \mathrm{~W} / \mathrm{cm}^{3}$ iken, $\lambda=24$ için bu değer $2.6683 \mathrm{~W} / \mathrm{cm}^{3}$ olarak belirlenmektedir.

- $\quad$ Artan ısı taşınım katsayı ile oyuğun kanat performans parametrelerine olan etkisi düşmektedir.
- Düşük ısı taşınım katsayıları için kanat verimi ve etkinliği değerleri klasik ve oyuklu kanatta yakın sonuçlar vermektedir. Artan $\lambda$ değeri ile hem $\eta$ hem de $\varepsilon$ üstel olarak azalmaktadır.

- $\mathrm{h}=25,50$ ve $100 \mathrm{~W} / \mathrm{m}^{2} \mathrm{~K}$ için konvansiyonel kanat verimi sırasıyla \%82.0, \%70.3 ve $\% 55.9$ olarak hesaplanmıştır. Oyuklu kanatta ise $\lambda=24$ için ilgili değerler \%79.0, \%66.3 ve \%51.7 olarak elde edilmiştir.

- $\quad \mathrm{h}=25,50$ ve $100 \mathrm{~W} / \mathrm{m}^{2} \mathrm{~K}$ için konvansiyonel kanat etkinliği sırasıyla 91.0, 78.1 ve 62.1 olarak hesaplanmıştır. Bu değerler oyuklu kanatta $\lambda=24$ için 87.7, 73.6 ve 57.4 olarak elde edilmiştir.

- Hafifliğin ve birim hacim başına ısı atımının önem arz ettiği soğutma uygulamalarında oyuklu kanat tasarımlarının kullanımı tavsiye edilmektedir.

\section{Kaynaklar}

Ali, H.M., Ashraf, M.J., Giovannelli, A., Irfan, M., Irshad, T.B., Hamid, H.M., Hassan, F. and Arshad, A., 2018. Thermal management of electronics: An experimental analysis of triangular, rectangular and circular pin-fin heat sinks for various PCMs. International Journal of Heat and Mass Transfer, 123, 272-284.

Azarkish, H., Sarvari, S.M.H. and Behzadmehr, A., 2010. Optimum geometry design of a longitudinal fin with volumetric heat generation under the influences of natural convection and radiation. Energy Conversion and Management, 51, 1938-1946.

Bakhti, F.Z. and Si-Ameur, M., 2019. A comparison of mixed convective heat transfer performance of nanofluids cooled heat sink with circular perforated pin fin. Applied Thermal Engineering, 159, 113819.

Cuce, E. and Cuce, P.M., 2013a. Effects of concavity level on heat loss, effectiveness and efficiency of a longitudinal fin exposed to natural convection and radiation. International Journal of Numerical Methods for Heat and Fluid Flow, 23 (7), 1169-1178.

Cuce, P.M. and Cuce, E., 2013b. Passive cooling of building-integrated photovoltaics (BIPVs) for better electrical performance. MEGS IV Annual Conference, Public Engagement with Energy. 12-13 September 2013, Loughborough, United Kingdom.

Cuce, E. and Cuce, P.M., 2013c. Tilt angle optimization of building-integrated photovoltaics (BIPVs) for cooler operating temperatures. MEGS IV Annual Conference, Public Engagement with Energy. 12-13 September 2013, Loughborough, United Kingdom. 
Cuce, E., Oztekin, E.K. and Cuce, P.M., 2019. Heat transfer enhancement in cylindrical fins through longitudinal parabolic perforations. International Journal of Ambient Energy, 40 (4), 406-412.

Cuce, P.M. and Cuce, E., 2014. Optimization of configurations to enhance heat transfer from a longitudinal fin exposed to natural convection and radiation. International Journal of Low-Carbon Technologies, 9 (4), 305-310.

Grubisic-Cabo, F., Nizetic, S., Coko, D. and Kragic, I.M., 2018. Experimental investigation of the passive cooled free-standing photovoltaic panel with fixed aluminum fins on the backside surface. Journal of Cleaner Production, 176, 119-129.

Guo, K., Zhang, N. and Smith, R., 2018. Design optimisation of multi-stream plate fin heat exchangers with multiple fin types. Applied Thermal Engineering, 131, 30-40.

Ibrahim, T.K., Mohammed, M.N., Mohammed, M.K., Najafi, G., Sidik, N.A.C., Basrawi, F., Abdalla, A.N. and Hoseini, S.S., 2018. Experimental study on the effect of perforations shapes on vertical heated fins performance under forced convection heat transfer. International Journal of Heat and Mass Transfer, 118, 832-846.

Incropera, F.P. and DeWitt, D.P., 2010. Isı ve kütle geçişinin temelleri (4. Basım). Taner Derbentli (çeviri editörü), Literatür Yayıncılık, 400-500.

Kobus, C.J. and Cavanaugh, R.B., 2006. A theoretical investigation into the optimal longitudinal profile of a horizontal pin fin of least material under the influence of pure forced and pure natural convection with a diameter-variable convective heat transfer coefficient. Journal of Heat Transfer, 128 (8), 843846.

Maji, A., Bhanja, D., Patowari, P.K. and Kundu, B., 2019. Thermal analysis for heat transfer enhancement in perforated pin fins of various shapes with staggered arrays. Heat Transfer Engineering, 40, 295-319.

Nadooshan, A.A., Kalbasi, R. and Afrand, M., 2018. Perforated fins effect on the heat transfer rate from a circular tube by using wind tunnel: An experimental view. Heat and Mass Transfer, 54, 3047-3057.

Yang, X., Lu, Z., Bai, Q., Zhang, Q., Jin, L. and Yan, J., 2017. Thermal performance of a shell-and-tube latent heat thermal energy storage unit: Role of annular fins. Applied Energy, 202, 558-570. 